\title{
Occurrence of Aflatoxin M1 in raw, pasteurized and UHT milk from Punjab, India
}

\author{
Anil Patyal ${ }^{1,2, *}$, Jatinder Paul Singh Gill ${ }^{2}$, Jasbir Singh Bedi ${ }^{2}$ and \\ Rabinder Singh Aulakh ${ }^{2}$ \\ ${ }^{1}$ Department of Veterinary Public Health and Epidemiology, College of Veterinary Science and A.H., CGKV, Anjora, Durg, \\ Chhattisgarh 491 001, India \\ ${ }^{2}$ School of Public Health and Zoonoses, Guru Angad Dev Veterinary and Animal Sciences University, Ludhiana, Punjab 141 004, India
}

\begin{abstract}
Aflatoxin M1 (AFM1) is a toxic and carcinogenic metabolite secreted in milk of dairy animals which have consumed the aflatoxin B1 contaminated feedstuff. In this study, 230 different types of milk samples comprising raw, pasteurized and ultra-high temperature treated milk were collected from three different geographical sites of Punjab during different seasons and analysed for the presence of AFM1 by using ELISA as screening, and HPLC with fluorescence detection as confirmatory method. Of total, $51 \%$ samples were detected positive for AFM1, while 45\% and $38 \%$ samples were found with AFM1 levels higher than the tolerance limits established by the European commission and Food safety and standard authority of India respectively. Results of study indicated a high incidence and levels of AFM1 in different types of milk during all seasons. Owing to this, there is a potential risk of liver cancer in people of Punjab, India especially children due to milk consumption. Therefore, strict regulatory actions are urgently required to control AFM1 level in milk below the legal standard limits. There is need to initiate routine examination of dairy animal feeds for aflatoxins to reduce animal and consequently human exposure.
\end{abstract}

Keywords: Aflatoxin M1, India, pasteurized milk, raw milk, UHT milk.

AFLATOXINS are closely related bisdihydrofurano metabolites produced by certain strains of Aspergillus flavus, Aspergillus parasiticus and Aspergillus nomius fungus. Aflatoxins are one of the most important mycotoxins because they are extremely toxigenic, mutagenic and carcinogenic in nature ${ }^{1}$. While more than 20 types of aflatoxins have been reported, the four major ones are aflatoxin B1 (AFB1), aflatoxin B2 (AFB2), aflatoxin G1 (AFG1), and aflatoxin G2 (AFG2) based on their fluorescence under UV light. Among all aflatoxins, AFB1 has the greatest carcinogenic potential and is the most common aflatoxin produced by aflatoxigenic fungi ${ }^{2}$. It is absorbed in the gastrointestinal tract of animals that ingest contaminated feed and subsequently bio-transformed/

*For correspondence. (e-mail: anilvet01@gmail.com) hydroxylated by microsomal enzymes in the cytochrome P-450 enzyme superfamily to form aflatoxin M1 (AFM1), which is secreted in milk. The ability of dairy animals to convert AFB1 present in feed to AFM1 secreted in milk has been well documented; demonstrating transformation rates in dairy cows milked twice in a day was usually 1$2 \%$ of the ingested AFB 1 for low-yielding cows and up to $6 \%$ for high-yielding cows ${ }^{3}$. The AFM1 appears in milk within $12-24 \mathrm{~h}$ after the first AFB1 ingestion by lactating animals; however, its level may return to unnoticeable within $72 \mathrm{~h}$ after cessation of the AFB1 contaminated feed $^{4}$. International agency for research on cancer (IARC) classified AFB1 as a Group I carcinogen (carcinogenic to humans $)^{5}$. Although AFM1 has 10 times less carcinogenic potential than AFB1, it still can pose threat to humans, especially for children considering their high milk consumption and lower body weight ${ }^{5}$. Considering the health effects of AFM1, IARC reclassified its category and changed it from Group 2B (possibly carcinogenic to humans) to Group I (carcinogenic to humans) ${ }^{6}$. The World Health Organization (WHO) recommended the reduction of AFM1 content in milk and milk products to a minimum level, in order to minimize the potential risk it poses for the consumers ${ }^{7}$.

Long-term dietary exposure to aflatoxins is a major risk factor for development of hepatocellular carcinoma (HCC) and it has been studied that around $27 \%$ of the HCC cases reported in Southeast Asia are aflatoxins induced $^{8}$. Human susceptibility to aflatoxicosis varies with age, health and level and duration of exposure. In particular, infants and young children are the most vulnerable population to the harmful effects of AFM1 due to their low body weight, high metabolic rate, low detoxifying capacity and incomplete development of vital organs and tissues, especially the central nervous system $^{9}$. For children, however, the cancer risk is of less concern than is the partial immune system suppression and the developmental (physical and mental) stunting that often accompany chronic exposure to sub-acute levels of aflatoxins. The association between impaired child growth/stunting and aflatoxins exposure have been reported from many countries ${ }^{10,11}$. Due to the potential health hazards for humans, several countries have established 
maximum permissible limit (MPL) for AFM1 in milk. The European Commission (EC) has established a MPL of $50 \mathrm{ng} / 1$ for AFM1 in milk, whereas United States Food and Drug Administration (USFDA) and Food Safety and Standard Authority of India (FSSAI) have established the MPL at $500 \mathrm{ng} / \mathrm{l}$ (refs 12, 13).

Although there are contradictory reports in the literature on the effects of various heat treatments on AFM1 content in milk, with AFM1 generally regarded as heat stable $^{14,15}$. AFM1 has been regarded as one of the major important xenobiotic compounds detected in heat treated milk and other milk products because of its high thermo stability during different processing such as pasteurization and ultra high temperature (UHT) treatment ${ }^{16}$. The incidence and levels of AFM1 in milk and milk products may change according to the topographical location, country development level and climatic conditions so it is important to assess the incidence and contamination levels of AFM1 in milk produced in different locations ${ }^{17}$.

India is a tropical country and has all the conditions which are conducive for the growth of aflatoxin producing fungi. The occurrence of AFM1 in milk has been reported by several studies conducted in different states of India such as Utter Pradesh ${ }^{18}$, Karnataka and Tamil $\mathrm{Nadu}^{19}$, Goa ${ }^{20}$ and Maharashtra ${ }^{21}$. However, there has been meagre information available on the occurrence and levels of AFM1 in milk from Punjab, which is a progressive agrarian state of India. Among different states, Punjab stands first in terms of per capita milk availability (1075 grams/day) and 6th in milk production in the country $^{22}$. Moreover, Punjab ranks second in terms of monthly per capita milk consumption in the country ${ }^{23}$.

Therefore, the objective of this study was to assess the occurrence of AFM1 in different types of milk and to evaluate its geographical and seasonal difference in Punjab, India. The results of this study will facilitate continuous surveillance, future risk analysis and management of AFM1 in milk to protect public health.

\section{Materials and methods}

\section{Sample collection}

A total of 230 different milk samples comprising raw $(n=110)$, pasteurized $(n=80)$ and UHT $(n=34)$ milk were collected from three different geographical sites of Punjab state from March 2017 to February 2018 during the summer, rainy and winter seasons. Raw milk samples were collected from local milk vendors while pasteurized and UHT milk samples of different brands with different manufacturing batches were purchased from local retail markets of three sites. These brands of pasteurized and UHT milk are also sold all over India. All the collected milk samples were transported to the laboratory within $24 \mathrm{~h}$ at temperature of less than $4^{\circ} \mathrm{C}$. Further, in the labo- ratory, raw milk samples were stored at $-20^{\circ} \mathrm{C}$ while pasteurized and UHT milk samples were stored at $4^{\circ} \mathrm{C}$ and room temperature respectively, till analysis.

\section{Standard and reagents}

HPLC grade solvents namely, methanol (MeOH) and acetonitrile $(\mathrm{ACN})$ were purchased from Merck (Mumbai, India). Milli-Q ultra pure water (Merck millipore water purification system, Darmstadt, Germany) was used during all analysis. AFM1 standard (Catalogue No. CRM46319) with 98\% chromatographic purity was procured from Supelco (Sigma-Aldrich, Bellifonte, PA, USA). AFM1 standard stock solution was prepared in $\mathrm{ACN}$ and standard working solutions were prepared in $10 \%$ ACN solution.

\section{Analysis of milk samples for AFM1 by ELISA}

Aflatoxin M1 ELISA Test Kits (Catalog No. 5121AFM) were procured from Euro Proxima (EuroProxima B.V., Beijerinckweg, The Netherlands) with following specifications: limit of detection (LOD) ( $5 \mathrm{ng} / \mathrm{l})$ and crossreactivity for aflatoxin $\mathrm{M} 1$ and $\mathrm{M} 2$ was $100 \%$ and $<20 \%$ respectively. Each test kit was supplied with AFM1 antibody coated microtitre plates, buffer solutions, substrate solution, stop solution, conjugate solution, AFM1 free skim milk and AFM1 standard solutions: 0, 6, 12, 25, 50, 100 and $200 \mathrm{ng} / \mathrm{l}$. All milk samples were prepared and analysed quantitatively for AFM1 according to the manufacturer's instructions. All AFM1 standard solutions, blanks and skimmed milk samples were added $(100 \mu \mathrm{l}$ each) to the duplicate wells of microtiter plate. $\mathrm{A}_{450}$ was measured with an ELISA reader on a microplate spectrophotometer (Thermo Scientific ${ }^{\mathrm{TM}}$ Multiskan ${ }^{\mathrm{TM}}$, Thermo Fisher Scientific, Waltham, MA, USA). The measured $\mathrm{A}_{450}$ was conversely proportional to the AFM1 concentrations in the milk samples. AFM1 levels in tested milk samples were estimated by interpolating values on a six point calibration curve.

The ELISA screening method was validated following guidelines in European Commission Decision 657/2002/ $\mathrm{EC}^{24}$ and parameters taken into account were: linearity, detection limit, accuracy (recovery) and precision (repeatability). Linearity of the calibration curve was tested by plotting the mean relative absorbance percentage obtained from each reference standard against its corresponding concentration on the calibration curve. Limit of detection (LOD) for the ELISA assay was determined by following the manufacturer's instructions. Mean recovery values and repeatability were determined by spiking known negative milk samples at three different levels (three replicates at each level) $-50 \mathrm{ng} / \mathrm{l}, 100 \mathrm{ng} / \mathrm{l}$ and $200 \mathrm{ng} / \mathrm{l}$. 
Analysis of milk samples for AFM1 by HPLC-FLD

Milk samples were purified using AflaStar ${ }^{\mathrm{TM}}$ M1 Rimmune-affinity columns (Romer Labs Inc., Stylemaster Drive Union, USA) following the manufacturer's protocol.

HPLC-FLD analysis was performed on an Agilent 1260 infinity HPLC system as per the protocol given by EN ISO 14501:2007 (ref. 25) for AFM1 with slight modifications using the Waters $^{\circledR}$ Spherisorb $^{\circledR}$ C-18 $(250 \times 4.6 \mathrm{~mm}$ I.D., $5 \mu \mathrm{m}$ particle size $)$ reverse phase analytical column, set at $40^{\circ} \mathrm{C}$. AFM1 elution was done under isocratic conditions with water and acetonitrile $(67 / 33, \mathrm{v} / \mathrm{v})$ as the mobile phase at a flow rate of $1.2 \mathrm{ml} / \mathrm{min}$. After injecting $20 \mu \mathrm{l}$ of sample elute, FLD monitored the eluent for AFM1 at excitation wavelength of $365 \mathrm{~nm}$ and emission wavelength of $435 \mathrm{~nm}$. OpenLAB EZChrom software (Agilent Technologies International Pvt Ltd, Santa Clara, USA) was used for instrument control and data evaluation.

The HPLC-FLD method was validated for linearity, LOD, limit of quantification (LOQ), accuracy, precision and selectivity following European Commission Decision $657 / 2002 / \mathrm{EC}^{24}$. Linearity was evaluated by plotting five point solvent matched calibrations in triplicate for AFM1 standard solutions in the concentration range of 50 $800 \mathrm{ng} / \mathrm{l}$. Calibration curves were drawn by plotting peak area against AFM1 concentrations, and linearity was determined by linear regression analysis. The LOD and LOQ were calculated from the calibration curve in the concentration range corresponding to the lower concentration levels as per the MPL established for AFM1 in milk by FSSAI. LOD and LOQ were calculated by using equations given by International Conference on Harmonization $^{26}: \mathrm{LOD}=3.3 \times \sigma / \mathrm{m}$ and $\mathrm{LOQ}=10 \times \sigma / \mathrm{m}$, where $m=$ slope of the calibration curve and $\sigma=$ residual standard deviation. Recovery experiments were carried out by spiking known negative milk samples with working standard solutions of AFM1 at three fortification levels: 200, 500 and $1000 \mathrm{ng} / \mathrm{l}$ with three replicates for each level. Repeatability of the method was calculated in terms of the percent relative standard deviation (\% RSD). Repeatability was assessed by injecting three similar extractions of blank milk samples fortified with AFM1 at same as well as at different fortification levels. Method selectivity was determined by analysing AFM1 negative milk sample and a reagent blank to ascertain if there was any interference from endogenous substances around the retention time window of AFM1.

\section{Statistical analysis}

All statistical analyses were carryed out using Microsoft Excel and SPSS for Windows 20.0.0 (SPSS Inc., 2007, Chicago, Illinois, USA). Mean, standard deviations, \% RSD, maximum and minimum concentration, and coefficient of determination $\left(r^{2}\right)$ were calculated for AFM1 using descriptive statistics. Differences in mean levels of AFM1 between different types of milk samples tested during different seasons from all three districts were analysed by using a one way analysis of variance (ANOVA) with post hoc Tukey's test at $95 \%$ mean confidence interval. The relationship between occurrence of AFM1 in milk samples and season, or location or type of milk was calculated with a Chi-square test.

\section{Results}

\section{Validation of ELISA and HPLC-FLD methods for AFM1}

For the ELISA assay, the LOD for AFM1 was $5 \mathrm{ng} / \mathrm{l}$. The calibration curve for AFM1 was linear $\left(r^{2}=0.99\right)$ from 6 to $200 \mathrm{ng} / \mathrm{l}$. The percent AFM1 recovered ranged from $88 \%$ to $94 \%$ while the $\%$ relative SD was between $2.5 \%$ and $6.4 \%$ (Table 1). The ELISA method performance parameters were consistent with the regulatory requirements ${ }^{25}$. The solvent matched calibration curve for the HPLC-FLD method for AFM1 standard solutions exhibited good linearity with a $r^{2}$ value of 0.99 over the concentration range of 50 to $800 \mathrm{ng} / \mathrm{l}$. The LOD and LOQ values were $40 \mathrm{ng} / \mathrm{l}$ and $100 \mathrm{ng} / \mathrm{l}$ respectively, and were lower than the MPL for AFM1 in India $(500 \mathrm{ng} / \mathrm{l})$. The mean recoveries of AFM1 were between $81 \%$ and $84 \%$ with precision between $3.2 \%$ and $5.4 \%$ (Table 1 ). Since, the recoveries and \% RSD were within the $\mathrm{EC}^{27}$ limits of 70 $120 \%$ and $<20 \%$ respectively, the optimized and validated HPLC-FLD method used in this study was considered to be both accurate and precise. The HPLC-FLD chromatograms had good resolution for AFM1 and there were no interfering peaks from the matrix in the retention time window of AFM1. Thus, the method was selective for the detection and confirmation of AFM1 in milk samples.

\section{Occurrence of AFM1 in milk samples}

All milk samples were first screened with the ELISA assay. Samples were considered positive when the AFM1

Table 1. Recovery and relative standard deviation data for Aflatoxin M1 (AFM1) in milk

\begin{tabular}{lccc}
\hline Method & $\begin{array}{c}\text { Fortification } \\
\text { level (ng/l) }\end{array}$ & Recovery (\%) & $\begin{array}{c}\text { Relative standard } \\
\text { deviation (RSD \%) }\end{array}$ \\
\hline ELISA & 50 & 88 & 5.4 \\
& 100 & 94 & 2.5 \\
HPLC-FLD & 200 & 93 & 6.4 \\
& 200 & 81 & 3.7 \\
& 500 & 82 & 5.4 \\
& 1000 & 84 & 3.2 \\
\hline
\end{tabular}

${ }^{\mathrm{a}}$ Three replicates at each level. 
Table 2. Occurrence of AFM1 in different types of milk samples in different seasons and districts from Punjab, India

\begin{tabular}{|c|c|c|c|c|c|c|c|}
\hline \multirow[b]{2}{*}{ Categories } & \multirow[b]{2}{*}{$N$} & \multirow[b]{2}{*}{$n(\%)^{\mathrm{a}}$} & \multicolumn{4}{|c|}{ AFM1 concentration in positive samples (ng/l) } & \multirow{2}{*}{$\begin{array}{l}\text { Percentage of samples above } \\
\text { FSSAI MPL }(500 \mathrm{ng} / \mathrm{l})\end{array}$} \\
\hline & & & $5-50(\%)$ & $>50^{\mathrm{b}}(\%)$ & Range $^{c}$ & $\operatorname{Mean}^{\mathrm{d}} \pm \mathrm{SD}$ & \\
\hline \multicolumn{8}{|l|}{ Type of milk } \\
\hline Raw & 116 & 60 & 7 & 53 & $9-4185$ & $960 \pm 610$ & 47 \\
\hline Pasteurized & 80 & 41 & 5 & 36 & $6-2330$ & $850 \pm 590$ & 28 \\
\hline UHT & 34 & 47 & 6 & 41 & $9-2585$ & $810 \pm 490$ & 35 \\
\hline \multicolumn{8}{|l|}{ Season } \\
\hline Summer & 75 & 45 & 5 & 40 & $9-1780$ & $740 \pm 460^{\mathrm{A}}$ & 31 \\
\hline Rainy & 80 & 58 & 4 & 54 & $25-4185$ & $1140 \pm 690^{\mathrm{B}}$ & 48 \\
\hline Winter & 75 & 51 & 10 & 41 & $6-2195$ & $870 \pm 610$ & 36 \\
\hline \multicolumn{8}{|l|}{ District } \\
\hline Ludhiana & 110 & 52 & 6 & 46 & $9-4185$ & $885 \pm 570$ & 38 \\
\hline Bathinda & 60 & 48 & 8 & 40 & $6-2580$ & $965 \pm 690$ & 37 \\
\hline Amritsar & 60 & 53 & 5 & 48 & $9-2410$ & $905 \pm 550$ & 40 \\
\hline
\end{tabular}

$n^{\mathrm{a}} \mathrm{A}$ milk sample was considered positive when its AFM1 concentration exceed $5 \mathrm{ng} / \mathrm{l}$, which was the detection limit of ELISA screening method. ${ }^{b}$ Milk samples were over the EC MPL (50 ng/l) for AFM1, further confirmed and quantified with confirmatory HPLC-FLD method. ${ }^{\mathrm{c}}$ Minimum-maximum. ${ }^{\mathrm{d}}$ Positive sample mean \pm standard deviation. Means followed by different letters (A, B) in two seasons are significantly different $(P<0.05)$. AFM1, Aflatoxin M1; FSSAI, Food safety and standard authority of India; MPL, Maximum permissible limit; N, Total number of samples were tested with ELISA; SD, Standard deviation.

Table 3. Frequency distribution of AFM1 positive milk samples

\begin{tabular}{lc}
\hline $\begin{array}{l}\text { Range of AFM1 } \\
\text { concentration (ng/l) }\end{array}$ & $\begin{array}{c}\text { Number of positive } \\
\text { samples }(\%)\end{array}$ \\
\hline $5-50$ & 12 \\
$50-500$ & 14 \\
$500-1000$ & 30 \\
$1000-2000$ & 37 \\
$>2000$ & 8 \\
\hline
\end{tabular}

concentration was $>5 \mathrm{ng} / \mathrm{l}$. Samples with concentrations above the EC MPL (50 ng/l) were considered noncompliant and were further quantified by HPLC-FLD method.

Two hundred and thirty milk (raw, pasteurized and UHT) samples were analysed for occurrence of AFM1 (Table 2). Out of total samples analysed, 118 (51\%) positive samples (mean level of $940 \mathrm{ng} / \mathrm{l}), 104$ (45\%) exceeded the EC MPL and $88(38 \%)$ of exceeded the FSSAI MPL. Range of AFM1 concentration in positive milk samples is presented in Table 3 . Highest frequency of AFM1 contaminated samples was found in raw milk samples followed by UHT milk and least in pasteurized milk samples, with mean levels of $960 \mathrm{ng} / 1,810 \mathrm{ng} / \mathrm{l}$ and $850 \mathrm{ng} / \mathrm{l}$ respectively. There was no significant difference $(P>0.05)$ observed among the mean levels of AFM1 in three types of milk, but chi-square test revealed that the proportion of contaminated samples varied by type of milk $(P<0.05)$. AFM1 levels $>5 \mathrm{ng} / \mathrm{l}$ were found in $60 \%$, $41 \%$ and $47 \%$ of raw, pasteurized and UHT milk samples respectively. $53 \%, 36 \%$ and $41 \%$ of raw, pasteurized and UHT milk samples respectively were contaminated with
AFM1 at levels >EC MPL and 47\%, 28\% and 35\% of raw, pasteurized and UHT milk samples respectively, exceeded the FSSAI MPL.

Milk samples were most frequently contaminated with AFM1 in rainy season (58\%) followed by winter (51\%) and the summer $(45 \%)$ (Table 2$)$, but these frequencies were not significantly different from one another $(P>0.05)$. But, the mean levels of AFM1 in analysed milk samples were found significantly higher during rainy season $(1140 \mathrm{ng} / \mathrm{l})$ compared to summer season (740 ng/l). AFM1 levels in winter milk samples were also found high $(870 \mathrm{ng} / \mathrm{l})$ than summer milk, but levels were not found significantly different $(P>0.05)$. The occurrence and levels of AFM1 detected in milk samples from different sites were not significantly different.

\section{Discussion}

The occurrence of AFM1 in milk is a matter of great concern worldwide because of the human health related issues. This study showed that milk, whether it is raw, pasteurized or UHT is contaminated with AFM1 in Punjab, India and $45 \%$ of samples exceeded the limit of $50 \mathrm{ng} / 1$ set by the EC and $38 \%$ of FSSAI, MPL. In India, hot and humid climatic conditions are favourable for fungal invasion, growth and production of mycotoxins including aflatoxins in food and feed commodities. Unseasonal rains and floods are very common, and this increases the moisture content of the grains and other feedstuff, and therefore their susceptibility to fungal $\operatorname{attack}^{28}$. Indeed, many reports have showed the presence of high concentrations of aflatoxins in dairy animals feed and ingredients in India ${ }^{29-32}$. Most dairy farmers in India 
RESEARCH ARTICLES

Table 4. Occurrence of AFM1 in raw milk samples in different countries

\begin{tabular}{|c|c|c|c|c|c|}
\hline Country & $N$ & $\mathrm{n}^{\mathrm{a}}(\%)$ & $\begin{array}{c}\text { Samples above } \\
\text { EC MPL }(50 \mathrm{ng} / \mathrm{l})(\%)\end{array}$ & $\begin{array}{l}\text { Samples above USFDA } \\
\text { MPL (500 ng/l) }(\%)\end{array}$ & Reference \\
\hline Syria & 74 & 95 & 59 & 21 & 33 \\
\hline Sudan & 44 & 96 & 96 & 83 & 34 \\
\hline Pakistan & 107 & 71 & 24 & Not reported & 35 \\
\hline Pakistan & 520 & 93 & 53 & 0 & 36 \\
\hline Serbia & 40 & 95 & 75 & 13 & 37 \\
\hline Serbia & 678 & 80 & 56 & 25 & 38 \\
\hline Iran & 170 & 100 & Not reported & 34 & 39 \\
\hline Ethiopia & 100 & 100 & 92 & 26 & 40 \\
\hline Turkey & 176 & 30 & 17 & 3 & 41 \\
\hline India & 45 & 100 & 49 & 13 & 19 \\
\hline India & 116 & 60 & 53 & 47 & This study \\
\hline
\end{tabular}

$\mathrm{N}$, Total number of samples analysed; $\mathrm{n}^{\mathrm{a}}$, Number of positive samples.

feed cereals (maize, wheat, etc.) or agricultural or oilseed by-products (peanuts, soybean, etc.) to their dairy animals and these aflatoxin susceptible feed materials constitute $>70 \%$ of cattle feed ${ }^{28}$. Inclusion of AFB1 contaminated feedstuff in a dairy animal's diet increases the chances of significant AFM1 contamination in the milk.

The European Commission sets the MPL to $5 \mu \mathrm{g} / \mathrm{kg}$ for AFB1 in complete feeds for dairy animals ${ }^{12}$ but currently there is no legal equivalent for livestock feed or fodder in India. The levels and incidence of AFM1 in milk in developing countries like India are higher and more frequent than in developed countries. This difference could have several causes, including lack of regulations on aflatoxins in dairy animals feed and milk products, unawareness of the problem amongst dairy farmers, inadequate analytical facilities, improper farm managemental practices, and lack of suitable feed storage facilities.

The percentage of AFM1 contaminated raw milk samples in the current study was similar to previous reports from

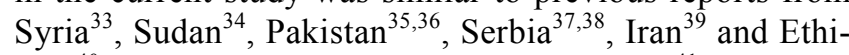
opia $^{40}$ and higher than that reported in Turkey ${ }^{41}$ (Table 4).

Amongst current pasteurized milk samples $41 \%$ were contaminated. The occurrence is less than that reported from Syria ${ }^{33}$, Brazil ${ }^{42}$, Iran ${ }^{43,44}$, Lebanon ${ }^{45}$, Kosovo ${ }^{46}$ and China $^{47}$ (Table 5), although the contamination levels of AFM1 in samples in this study were higher than those reported in all of the others except for Brazil ${ }^{42}$.

The percentage of samples that exceeds the EC MPL for AFM1 in this study was fewer than those from Bra$\mathrm{zil}^{42}, \operatorname{Iran}^{44}$, Turkey ${ }^{48}$ but higher than those from other studies $^{43,46,49,50}$ (Table 6). There are relatively few previous reports ${ }^{19,20}$ of AFM1 in milk from different parts of India and the results are similar to ours. They found that $100 \%$ of raw milk samples, $64 \%$ of UHT milk and 43 $100 \%$ of pasteurized milk samples were AFM 1 contaminated. These differences in the contamination percentage and levels of AFM1 in milk among different countries may be attributable to different factors such as dissimilarity in the level of AFB1 in feedstuffs that dairy animals consume, different geography and climate, differences in feeding systems, dairy farm managemental practices, analytical methods used in investigations, MPLs established for aflatoxins in milk and dairy animals feedstuff, and implementation of food safety system in dairy sector. The prevalence and levels of AFM1 in milk and milk products may vary according to the geographical location, development level and climatic conditions of the country ${ }^{17}$.

In this study, mean levels of AFM1 obtained in raw milk were similar to those found in pasteurized and UHT milk (Table 2). In most areas in India, milk is not tested for AFM1 contamination prior to the receipt of the raw milk at milk collection centres or dairy cooperatives. Thus, raw milk from dairy farms with different AFM1 levels is mixed and could result in similar levels of AFM1 in pasteurized and UHT milk. The pasteurized and UHT milk samples analysed had a comparatively narrow range of AFM1 contamination compared to raw milk. This consistency could be due to blending of highly contaminated milk with less contaminated milk at milk collection centres.

The frequency and levels of AFM1 contamination also varied by season. The mean levels of AFM1 in analysed milk samples were highest during the rainy season (1140 ng/l), intermediate during the winter (870 ng/l) and lowest in summer $(740 \mathrm{ng} / \mathrm{l})$. The percentage of contaminated samples followed a similar pattern - highest in the rainy season $(58 \%)$, intermediate during the winter (51\%) and lowest in the summer $(45 \%)$. Results of the present study were consistent with those of Aslam et al. ${ }^{51}$ who analysed 485 milk samples for AFM1 in Pakistan and found that the highest mean levels of AFM1 were found in the autumn and monsoon seasons and the lowest mean levels were found in the summer. A number of other stu$\operatorname{dies}^{36,38,52}$, also reported that the mean levels of AFM1 in winter milk samples were found higher than in summer season.

The higher mean levels of AFM1 during the rainy/ monsoon season in this study might be attributable to the high temperature and humidity during the rainy season. These conditions promote the growth of aflatoxigenic 
Table 5. Occurrence of AFM1 in pasteurized milk samples in different countries

\begin{tabular}{|c|c|c|c|c|c|}
\hline Country & $N$ & $\mathrm{n}^{\mathrm{a}}(\%)$ & $\begin{array}{c}\text { Samples above } \\
\text { EC MPL }(50 \mathrm{ng} / \mathrm{l})(\%)\end{array}$ & $\begin{array}{l}\text { Samples above USFDA } \\
\text { MPL (500 ng/l) }(\%)\end{array}$ & Reference \\
\hline Syria & 10 & 100 & 80 & 60 & 33 \\
\hline Brazil & 12 & 58 & 58 & 58 & 42 \\
\hline Iran & 116 & 72 & 27 & 2 & 43 \\
\hline Iran & 220 & 85 & 70 & 2 & 44 \\
\hline Lebanon & 25 & 68 & 16 & 0 & 45 \\
\hline Kosovo & 84 & 83 & 21 & 0 & 46 \\
\hline China & 131 & 92 & 60 & 0 & 47 \\
\hline India & 7 & 43 & 43 & 43 & 19 \\
\hline India & 54 & 100 & 100 & 78 & 20 \\
\hline India & 80 & 41 & 36 & 28 & This study \\
\hline
\end{tabular}

$\mathrm{N}$, Total number of samples analysed; $\mathrm{n}^{\mathrm{a}}$, Number of positive samples.

Table 6. Occurrence of AFM1 in UHT milk samples in different countries

\begin{tabular}{lrcccc}
\hline Country & $N$ & $\mathrm{n}^{\mathrm{a}}(\%)$ & $\begin{array}{c}\text { Samples above } \\
\text { EC MPL }(50 \mathrm{ng} / \mathrm{l})(\%)\end{array}$ & $\begin{array}{c}\text { Samples above USFDA } \\
\text { MPL }(500 \mathrm{ng} / \mathbf{l})(\%)\end{array}$ & Reference \\
\hline Brazil & 15 & 67 & 67 & 67 & 42 \\
Iran & 140 & 66 & 54 & 2 & 44 \\
Turkey & 129 & 58 & 47 & 3 & 48 \\
India & 45 & 64 & 64 & 22 & 19 \\
India & 34 & 47 & 41 & 35 & 43 \\
Iran & 109 & 62 & 17 & 3 & 46 \\
Kosovo & 94 & 79 & 31 & 0 & 49 \\
Brazil & 75 & 31 & 20 & 31 & 50 \\
China & 153 & 55 & 4 & 0 & 53 \\
\hline
\end{tabular}

$\mathrm{N}$, Total number of samples analysed; $\mathrm{n}^{\mathrm{a}}$, Number of positive samples.

fungi and enable aflatoxin accumulation in the feed of dairy animals which can be transformed to AFM1 in the milk. There are number of studies ${ }^{53,54}$ from India reported that aflatoxin contamination in animal feed was highest during the monsoon and post-monsoon seasons. The socioeconomic conditions of the region such as poor or inappropriate feed storage, shortage of fresh green feed/fodder and large amount of stored feeds provided to dairy animals, also are an important contributor to the high occurrence of mycotoxins (aflatoxins) in animal feed $^{43,52,55,56}$. Inappropriately stored feeds with a higher possibility of containing AFB1 (such as concentrates, cereals, hay, etc.) are used in relatively larger amounts for feeding dairy animals during the winter season, which increases the AFM1 level in the milk ${ }^{57}$.

We found that contamination percentage and mean levels of AFM1 in tested milk samples were not influenced by location, which is consistent with the results of Hashemi $^{58}$. Thus, similar climatic conditions were present at all geographical sites and similar farm management practices were followed by most of the dairy farmers of Punjab.

Overall the results of present study suggest that residents of Punjab, India, especially children, are at very high risk of health problems associated with AFM1 in milk, regardless of whether the milk was raw, pasteurized or UHT processed. The limited geographic origin of the samples we evaluated means that our results may not be representative of the entire country and to know the exact magnitude of the problem in India, more studies of milk and milk products for AFM1 from different parts of the country are warranted. Nevertheless, Punjab is first in terms of per capita milk availability and 6th in milk production in the country, so the study is of national significance. The most convincing strategy to ensure absence or low levels of AFM1 in milk is to monitor and control the AFB1 content in dairy animals feed stuff. While developed countries effectively regulate the AFB1 level in dairy animals feed, thus ensuring the AFM1 level within the legal permissible limits in milk so such regulatory limits should also be established for AFB1 in dairy animals feed and fodder in India.

\section{Conclusion}

We found that more than $50 \%$ of the milk samples tested were contaminated with AFM1. AFM1 levels in 45\% and $38 \%$ of the contaminated milk samples exceeded the MPLs set by the EC and FSSAI respectively. In 37\% of the contaminated milk samples, the levels of AFM1 ranged from 1000 to $2000 \mathrm{ng} / \mathrm{l}$, which is 2-4 times higher 
than the MPL set by FSSAI and 20-40 times higher than EC MPL. We also found both high incidence and levels of AFM1 in different types of milk in all seasons. Thus, residents of Punjab, India especially children are at very high risk of exposure to AFM1 due to milk consumption. The most effective way to decrease the level of AFM1 in milk is, to reduce the AFB1 levels in dairy animal's feedstuff by improving the farm managemental practices. Strict regulatory actions are needed to reduce AFM1 levels in milk below the standard safety limits and more careful approaches are needed for the storage of dairy animal's feedstuff.

Conflicts of interest: The authors declare no conflict of interest.

1. EFSA (European Food Safety Authority). Opinion of the scientific panel on contaminants in the food chain on a request from the commission related to aflatoxin $\mathrm{B} 1$ as undesirable substance in animal feed. EFSA J., 2004, 39, 1-27.

2. IARC (International Agency for Research on Cancer). Some naturally occurring substances: food items and constituents, heterocyclic aromatic amines and mycotoxins. In: IARC monographs on the evaluation of the carcinogenic risk of chemicals to humans. Lyon, France: IARC Scientific Publication, 1993, 56, 245-395.

3. Britzi, M. et al., Carry-over of aflatoxin B1 to aflatoxin M1 in high yielding Israeli cows in mid- and late-lactation. Toxins, 2013, 5, 173-183.

4. Van Egmond, H. P., Aflatoxin M1: occurrence, toxicity, regulation. In Mycotoxins in Dairy Products, Elsevier Applied Science, New York, 1989, pp. 11-55.

5. IARC (International Agency for Research on Cancer). Some traditional herbal medicines, some mycotoxins, naphthalene and styrene. In: IARC monograph on the evaluation of carcinogenic risk to humans. Lyon, France: IARC Scientific Publication, 2002, 82, $171-300$.

6. IARC (International Agency for Research on Cancer). In IARC monographs on the evaluation of carcinogenic risks to humans: Chemical agents and related occupations. Lyon, France: IARC Scientific Publication, 2012, 100F, 224-248.

7. WHO (World Health Organization). Evaluation of certain mycotoxins in food (Fifty-sixth report of the Joint FAO/WHO Expert Committee on Food Additives). WHO Technical Report Series, No. 906, 2001.

8. Liu, Y. and Wu, F., Global burden of aflatoxin-induced hepatocellular carcinoma: a risk Assessment. Environ. Health Perspect., 2010, 118, 818-824.

9. Lombard, M. J., Mycotoxin exposure and infant and young child growth in Africa: what do we know? Ann. Nutr. Metab., 2014, 64, $42-52$.

10. Gong, Y. et al., Post-weaning exposure to aflatoxin results in impaired child growth: a longitudinal study in Benin, West Africa. Environ. Health Perspect., 2004, 112, 1334-1338.

11. Okoth, S. A. and Ohingo, M., Dietary aflatoxin exposure and impaired growth in young children from Kisumu District, Kenya: cross sectional study. Afr. J. Health Sci., 2004, 11, 43-54.

12. European Commission Regulation. Setting maximum levels for certain contaminants in food stuffs. 466/2001/EC, 2001, pp. 1-13; http://ec.europa.eu/food/fs/sfp/fcr/fcr 02 en.pdf

13. FSSAI (Food Safety and Standards Authority of India). Food Safety and Standards (Contaminants, toxins and residues) Regulations. 2011; http://www.fssai.gov.in/Portals/0/Pdf/Food\%20safety\%20 and $\% 20$ standards $\% 20$ (contaminats, $\% 20$ toxins $\% 20$ and $\% 20$ residues) \%20regulation, $\% 202011$.pdf.

14. Govaris, A., Roussi, V., Koidis, A. and Botsoglou, N. A., Distribution and stability of aflatoxin M1 during processing, ripening and storage of Telemes cheese. Food Addit. Contam., 2001, 18, 437-443.

15. Prandini, A., Tansini, G., Sigolo, S., Filippi, L., Laporta, M. and Piva, G., On the occurrence of aflatoxin M1 in milk and dairy products. Food Chem. Toxicol., 2009, 47, 984-991.

16. Tsakiris, I. N., Tzatzarakis, M. N., Alegakis, A. K., Vlachou, M. I., Renieri, E. A. and Tsatsakis, A. M., Risk assessment scenarios of children's exposure to aflatoxin M1 residues in different milk types from the Greek market. Food Chem. Toxicol., 2013, 56, 261-265.

17. Picinin, L. C. A., Cerqueira, M. M. O. P., Vargas, E. A., Lana, A. M. Q., Toaldo, I. M. and Bordignon-Luiz, M. T., Influence of climate conditions on aflatoxin M1 contamination in raw milk from Minas Gerais State, Brazil. Food Control, 2013, 31, 419-424.

18. Rastogi, S., Dwivedi, P. D., Khanna, S. K. and Das, M., Detection of aflatoxin M1 contamination in milk and infant milk products from Indian markets by ELISA. Food Control, 2004, 15, 287-290.

19. Siddappa, V., Nanjegowda, D. K. and Viswanath, P., Occurrence of aflatoxin $\mathrm{M}_{1}$ in some samples of UHT, raw and pasteurized milk from Indian states of Karnataka and Tamil Nadu. Food Chem. Toxicol., 2012, 50, 4158-4162.

20. Kanungo, L. and Bhand, S., A survey of aflatoxin M1 in some commercial milk samples and infant formula milk samples in Goa, India. Food Agric. Immunol., 2014, 25, 467-476.

21. Nile, S. H., Park, S. W. and Khobragade, C. N., Occurrence and analysis of aflatoxin M1 in milk produced by Indian dairy species. Food Agric. Immunol., 2016, 27, 358-366.

22. BAHFS (Basic Animal Husbandry and Fisheries Statistics). Department of animal husbandry, dairying \& fisheries, Ministry of agriculture and farmers welfare, Government of India, Krishi bhawan, New Delhi, India. 2017; http://www.dahd.nic.in/sites/ default/filess/Tables $\% 20$ of $\% 20$ BAH $\% 26 a m p \% 3 B F S \% 202017 \%$ $20 \% 281 \% 29 . p d f$

23. NSSO (National Sample Survey Office). Household consumption of various goods and services in India 2011-12, NSS 68th Round, Ministry of Statistics and Programme Implementation, Government of India, 2014; http://mospi.nic.in/sites/default/files/publication_reports/Report_no558_rou68 30june14.pdf

24. EC (European Commission). European Commission Decision 2002/657/EC of 12 August 2002 implementing Council Directive 96/23/EC concerning the performance of analytical methods and the interpretation of results. L 221. Official Journal of the European Communities, 2002, pp. 8-36.

25. EN ISO 14501:2007. Milk and milk powder-determination of aflatoxin M1 content - clean-up by immunoaffinity chromatography and determination by high-performance liquid chromatography. European Committee for Standardization, 2007.

26. ICH (International Conference on Harmonisation). Validation of Analytical Procedures: text and methodology, Q2 (R1). In Harmonised Tripartite Guideline. 2005; https://www.ich.org/ fileadmin/Public_Web_Site/ICH_Products/Guidelines/Quality/Q2 R1/Step4/Q2 R1 Guideline.pdf

27. EC (European Commission). European Commission Regulation (EC) No. 401/2006 of 23 February 2006 laying down the methods of sampling and analysis for the official control of the levels of mycotoxins in foodstuffs. Official J. Euro. Union, 2006, L70, 1234.

28. Goyal, R. K., Prevention and control of mycotoxins in foodgrains in India. In Mycotoxin Prevention and Control in Food Grains (eds Semple, R. L. et al.), Bankok: UNDP/FAO regional network inter-country cooperation on postharvest technology and quality control of food grains, ASEAN grain post-harvest programme. AGPP Publication, 1991. 
29. Sinha, K. K., Incidence of mycotoxins in maize grains in Bihar State, India. Food Addit. Contam., 1990, 7, 55-61.

30. Dhavan, A. S. and Choudary, M. R., Incidence of aflatoxins in animal feedstuffs: a decade's scenario in India. J. AOAC Int., 1995, 78, 693-698.

31. Vijayasamundeeswari, A., Mohankumar, M., Karthikeyan, M., Vijayanandraj, S., Paranidharan, V. and Velazhahan, R., Prevalence of aflatoxin B1 contamination in pre and post-harvest maize kernels, food products, poultry and livestock feeds in Tamil Nadu, India. J. Plant Prot. Res., 2009, 49, 221-224.

32. Ramesh, J., Sarathchandra, G. and Sureshkumar, V., Analysis of feed samples for aflatoxin B1 contamination by HPTLC - a validated method. Int. J. Curr. Microbiol. Appl. Sci., 2013, 2, $373-$ 377.

33. Ghanem, I. and Orfi, M., Aflatoxin M1 in raw, pasteurized and powdered milk available in the Syrian market. Food Control, 2009, 20, 603-605.

34. Elzupir, A. O. and Elhussein, A. M., Determination of aflatoxin M1 in dairy cattle milk in Khartoum State, Sudan. Food Control, 2010, 21, 945-946.

35. Iqbal, S. Z. and Asi, M. R., Assessment of aflatoxin M1 in milk and milk products from Punjab, Pakistan. Food Control, 2013, 30, 235-239.

36. Ismail, A., Riaz, M., Levin, R. E., Akhtar, S., Gong, Y. Y. and Hameed, A., Seasonal prevalence level of aflatoxin M1 and its estimated daily intake in Pakistan. Food Control, 2016, 60, 461465 .

37. Kos, J., Levic, J., Duragic, O., Kokic, B. and Miladinovic, I., Occurrence and estimation of aflatoxin M1 exposure in milk in Serbia. Food Control, 2014, 38, 41-46.

38. Tomasevic, I., Petrovic, J., Jovetic, M., Raicevic, S., Milojevic, M. and Miocinovic, J., Two year survey on the occurrence and seasonal variation of aflatoxin M1 in milk and milk products in Serbia. Food Control, 2015, 56, 64-70.

39. Norian, R., Mahmoudi, R., Porfarzaneh, A., Mashatian, F., Kaboudari, A., Mahalleh, S. F. R. P. and Katiraee, F., Determination of aflatoxin M1 levels in raw milk samples using ELISA and high-performance liquid chromatography in Qazvin, Iran. J. Mycol. Res., 2015, 2, 41-48.

40. Gizachew, D., Szonyi, B., Tegegne, A., Hanson, J. and Grace, D. Aflatoxin contamination of milk and dairy feeds in the Greater Addis Ababa milk shed, Ethiopia. Food Control, 2016, 59, 773779 .

41. Golge, O., A survey on the occurrence of aflatoxin M1 in raw milk produced in Adana province of Turkey. Food Control, 2014, 45, $150-155$.

42. Scaglioni, P. T., Becker-Algeri, T., Drunkler, D. and BadialeFurlong, E., Aflatoxin B1 and M1 in milk. Anal. Chim. Acta, 2014, 829, 68-74.

43. Fallah, A. A., Assessment of aflatoxin M1 contamination in pasteurized and UHT milk marketed in central part of Iran. Food Chem. Toxicol., 2010, 48, 988-991.

44. Tajik, H., Moradi, M., Razavi, R. S. M. and Hadian, M., Determination of aflatoxin M1 in pasteurized and UHT milk in WestAzerbaijan Province of Iran. J. Food Qual. Hazards Control, 2016, 3, 37-40.
45. Assem, E., Mohamad, A. and Oula, E. A., A survey on the occurrence of aflatoxin $\mathrm{M} 1$ in raw and processed milk samples marketed in Lebanon. Food Control, 2011, 22, 1856-1858.

46. Rama, A., Latifi, F., Bajraktari, D. and Ramadani, N., Assessment of aflatoxin M1 levels in pasteurized and UHT milk consumed in Prishtina, Kosovo. Food Control, 2015, 57, 351-354.

47. Xiong, J., Xiong, L., Zhou, H., Liu, Y. and Wu, L., Occurrence of aflatoxin B1 in dairy cow feedstuff and aflatoxin M1 in UHT and pasteurized milk in central China, Food Control, 2018, 92, 386390.

48. Unusan, N., Occurrence of aflatoxin M1 in UHT milk in Turkey. Food Chem. Toxicol., 2006, 44, 1897-1900.

49. Oliveira, C. P., Soares, N. F. F., Oliveira, T. V., Junior, J. C. B. and Silva, W. A., Aflatoxin M1 occurrence in ultra high temperature (UHT) treated fluid milk from Minas Gerais/Brazil. Food Control, 2013, 30, 90-92.

50. Zheng, N., Sun, P., Wang, J. Q., Zhen, Y. P., Han, R. W. and $\mathrm{Xu}, \mathrm{X}$. M., Occurrence of aflatoxin M1 in UHT milk and pasteurized milk in China market. Food Control, 2013, 29, 198-201.

51. Aslam, N., Tipu, M. Y., Ishaq, M., Cowling, A., McGill, D., Warriach, H. M. and Wynn, P., Higher levels of aflatoxin M1 contamination and poorer composition of milk supplied by informal milk marketing chains in Pakistan. Toxins, 2016, 8, 347; https://dx.doi.org/10.3390/toxins8120347.

52. Bahrami, R., Shahbazi, Y. and Nikousefat, Z., Aflatoxin M1 in milk and traditional products from west part of Iran: occurrence and seasonal variation with an emphasis on risk assessment of human exposure. Food Control, 2016, 62, 250-256.

53. Dutta, T. K. and Das, P., Isolation of aflatoxigenic strains of Aspergillus and detection of aflatoxin B1 from feeds in India. Mycopathologia, 2001, 151, 29-33.

54. Becha, B. B. and Devi, S. S., Aflatoxin levels in feeds and feed Ingredients of livestock and poultry in Kerala. J. Veterinary Anim. Sci., 2013, 44, 76-78.

55. Ranjan, K. S. and Sinha, A. K., Occurrence of mycotoxigenic fungi and mycotoxins in animal feed from Bihar, India. J. Sci. Food Agric., 1991, 56, 39-47.

56. Guo, L., Zheng, N., Zhang, Y., Du, R., Zheng, B. and Wang, J., A survey of seasonal variations of aflatoxin M1 in raw milk in Tangshan region of China during 2012-2014. Food Control, 2016, 69, 30-35.

57. Bilandzic, N. et al., Monitoring of aflatoxin M1 in raw milk during four seasons in Croatia. Food Control, 2015, 54, 331-337.

58. Hashemi, M., A survey of aflatoxin M1 in cow milk in Southern Iran. J. Food Drug Anal., 2016, 24, 888-893.

ACKNOWLEDGEMENTS. We thank Guru Angad Dev Veterinary Animal Sciences University, Ludhiana, Punjab (India) for providing the necessary facilities to conduct this research. This research did not receive any specific grant from funding agencies in the public, commercial, or not-for-profit sectors

Received 17 April 2019; revised accepted 13 September 2019

doi: $10.18520 / \mathrm{cs} / \mathrm{v} 118 / \mathrm{i} 1 / 79-86$ 